\title{
ESPACIOS DEL EXILIO EN LOS DIARIOS DE ZENOBIA CAMPRUBÍ
}

\author{
MERCEDES ACILLONA LÓPEZ \\ Universidad de Deusto \\ mercedes.acillona@deusto.es
}

RESUMEN: Desde su llegada a Cuba en 1937 hasta su fallecimiento en Puerto Rico en 1956 los diarios de Zenobia Camprubí recogen los años de exilio del matrimonio. Este exilio transcurre a través de tres puntos geográficos en el proceso de construcción de su identidad en el exilio: Cuba, los Estados Unidos y Puerto Rico. Este trabajo se centra en la vivencia del espacio exílico. El modo de vivir la tensión entre América y España diferencia el exilio de Zenobia y Juan Ramón. Zenobia ansía una integración en los Estados Unidos que se representa en la búsqueda obsesiva de una casa. Frente a este espacio interior, que se define como su "lugar", Zenobia encuentra su libertad en los espacios abiertos, los "no-lugares", que convierten el tránsito urbano en un espacio libre.

PALABRAS CLAVE: Zenobia Camprubí, exilio, espacio, Juan Ramón Jiménez, escritura autobiográfica. 


\section{EXILE SPACES IN ZENOBIA CAMPRUBÍ'S DIARIES.}

ABSTRACT: From her arrival in Cuba in 1937 with her husband, to her death in Puerto Rico in 1956, Zenobia Camprubí's diaries capture the couple's years in exile. This exile took them to three geographic locations that represent her identity process: Cuba, the United States and Puerto Rico. This article focuses on how she experiences space in the diaries she wrote during her exile. Zenobia and Juan Ramón differ in the way they live the tension between America and Spain, and this makes their exiles different. Zenobia longs for an integration in the United States, a desire that is represented in her obsessive search for a house. As opposed to this inner space, which is her "place", Zenobia finds her freedom in the open spaces, the "non-places" that transform urban space into a free space.

KEYWORDS: Zenobia Camprubí, exile, space, Juan Ramón Jiménez, autobiographical literature.

$\mathrm{E}_{\mathrm{cos}}^{\mathrm{n}}$ tre 1937 y 1956 recupera Zenobia Camprubí la abandonada costumbre infantil de escribir asiduamente las impresiones de la jornada en un diario. No deja de ser significativo que el retorno a este hábito se produzca precisamente en los años de su exilio a raíz del precipitado abandono de España al iniciarse la Guerra Civil. Los veinte años que comprenden estos diarios presentan largos períodos de interrupciones producidos por circunstancias biográficas especiales que dificultan la tarea del apunte cotidiano. Pese a estas lagunas, que la autora intenta subsanar mediante una síntesis de los acontecimientos omitidos, los Diarios permiten un recorrido detallado, directo, vivo y en primera persona de los años más intensos vividos por Zenobia junto a Juan Ramón. Dentro del inmenso marco de estudios sobre el exilio de las mujeres en el 39, y más en concreto de la especial relevancia que en estas adquiere la escritura autobiográfica, ${ }^{1}$ los diarios de Zenobia han sido objeto de diversos análisis a partir de su publicación. De ellos se ha estudiado la importante información sobre la producción literaria del poeta, los momentos de la guerra (Palau, 1992), los aspectos diarísticos (Caballé, 2012), las coincidencias entre mujeres republicanas (Saiz, 2010) y otros muchos elementos valorativos en lo vital y en lo literario (Cortés, 2008 y 2010). Pero los diarios no solo son paradigmáticos en su género sino que resultan un singular documento del exilio (Cedena, 2004a y 2004b), como también el exilio ofrece un escenario privilegiado para los textos autobiográficos. En los espacios de esta literatura exílica centramos estas páginas.

Un dilatado proceso de exilio (la nueva tierra, el nuevo hogar, el destino final) se desplegará en los Diarios de Zenobia en tres experiencias geográficas diferentes o tres espacios diferentes de vida. La primera, la nueva tierra, se corresponde con los primeros años de su expatriación en la isla de Cuba. Es un período en el que tiene sus ojos puestos en los Estados Unidos, lugar donde reside su familia, anidan sus recuerdos más amables de la infancia y se asienta su cultura, formación y mentalidad. La segunda, el nuevo hogar, se vincula especialmente con la etapa de reencuentro con Norteamérica. Será primero itinerante viajera, más tarde residente en la Florida y posteriormente terminará integrándose profesionalmente en Washington, sin olvidar sus numerosas estancias en Nueva York. Durante este tiempo largo ansiará el arraigo en una sociedad que siente como suya. La tercera, el destino final, representa la conciliación, dentro del territorio estadounidense, de sus raíces americanas con las hispanas, conjugadas en la identidad cultural de la isla de Puerto Rico. Pero este espacio isleño edénico se verá ensombrecido por las amenazas de su enfermedad.

1 Véase la inabarcable bibliografía existente sobre la literatura del yo y su relación con el exilio, y en especial con el exilio de las mujeres (textos inéditos que se han ido publicando en las dos últimas décadas). Remitimos a los trabajos de Masanet, Caballé, Romera Castillo, Mangini, Martínez, Inestrillas, Cividanes, Acillona, Zabala, Vilarós, etc., entre otros innumerables estudios.

UNED. REI, 3 (2015), pp. 101-131

ISSN 2340-9029 
Estos tres espacios geográficos significan la fuerza centrífuga y dispersadora del exilio. Frente a ella actúa una tensión contraria, cerrada sobre sí misma, una mirada atrás, hacia España (los preocupantes avatares de su guerra, la casa abandonada o un cobijo para el retorno). Más allá del recuerdo y del olvido, España les atraerá como la fuerza gravitatoria de sus vidas, el centro que recoge la dispersión de los esfuerzos y vicisitudes. Pero este centro gravitatorio no será igual en Zenobia y Juan Ramón. De ahí que la vivencia de los espacios sea distinta en ambos.

Un espacio exílico contemplado desde la mirada de Marc Augé, reservaría el término de "lugar" para el espacio propio, natal, vivido y trabajado; ese que le "da la apariencia de una segunda naturaleza" (Augé, 1993: 51) al sujeto que lo habita; es decir, la patria perdida. Los individuos necesitan pensar su identidad simbolizando en ese lugar los constituyentes de su identidad comunitaria o singular. Los "no lugares" se dicen de espacios donde el anonimato se impone o donde se asientan prolongadamente los refugiados de cualquier desastre humanitario, es decir los espacios del exilio. En el "no lugar" se crea soledad o indiferenciación (107). Para Juan Ramón España sería por excelencia el "lugar" antropológico, en tanto que América sería el "no lugar”, el paso por una superficie por donde resbalan anónimos, solitarios y despersonalizadores sus días. Para Zenobia, sin embargo, los límites entre España y América-su delimitación identitariapresentan una barrera más compleja. Un "lugar" requiere serlo "de identidad, relacional e histórico" (83), y Zenobia parece hallar estos atributos también en América. Su soledad cederá ante los tumultuosos pero familiares espacios neoyorkinos y su identidad se fortalecerá precisamente en sus tareas universitarias. Tiene en estos nuevos espacios un recuerdo viejo, una acogida afectiva o una labor que cumplir. Sin embargo, será largo el período en que sus días rueden sin significado en geografías cambiantes con las que no se identifica y donde es un ser anónimo y transeúnte. Los diarios significan un intento de construcción -y éstos son el relato de una construcción-, circunstancia que ha sido destacada por toda la crítica autobiográfica. Pero, además, esta escritura es la bisagra en la que se produce la creación de un lugar propio a partir de un "no lugar".

Por otro lado, estos Diarios son, en parte, el relato del exilio de Juan Ramón tanto como el suyo propio. Y Zenobia nos muestra que la vida de Juan Ramón transitará durante todo este tiempo por lo "no lugares", por espacios que no le pertenecen, de los que solo le salva en alguna medida el aislamiento en su obra poética. Solo la espiritualización de los espacios recién estrenados en sus procesos místicos, metamorfoseados en las evocaciones de España, le salvarán de la completa alienación de su identidad. Es decir, ambos comparten la escritura como el camino de apropiación de un espacio utópico en el que reconocerse. Si España es el "lugar" real y América solo lo es para Zenobia, la escritura sí es el "lugar" interior de sus vidas errantes. En el exilio todo gravita hacia el alma.

Si hay algo que la biografía exílica de estos Diarios pone de relieve es que el exilio presenta dos expresiones diferentes que nuevamente oponen un dinamismo excéntrico y otro concéntrico: el primero, vivido como exilio patrio, y el segundo, como exilio sentimental. $\mathrm{Mu}-$ cho más agudo en su alcance existencial será para ella este segundo exilio de vivencias interiores, de frustración íntima. Por el contrario, el exilio patrio será la experiencia más destructiva y desestabilizadora vivida por Juan Ramón. El exilio agudiza las diferencias - no las lima (Grillo, 2001: 325) —. Ambas caras del exilio se funden en una gran metáfora que constituye una de las referencias más insistentes de los Diarios de Zenobia, la casa, el hogar (Caballé, 2012). La casa se convierte durante años en una necesidad obsesiva que llena las páginas de sus cuadernos, siendo tanto tierra firme para su viaje a la deriva como límites espaciales desde los que afirmar su yo invadido. La casa representa el espacio de identidad por excelencia, por ello constituye "el lugar" en medio de una encrucijada de lugares ajenos, la posibilidad de apropiarse de un espacio en medio de una geografía alienadora. En todos los exilios de la humanidad, la casa ha sido el símbolo que sintetiza el sueño del regreso, las raíces que sustentan el yo esencial, el territorio que delimita las fronteras mismas del sujeto, 
lo propio. Donde existe un hogar, existe una costumbre, un regreso repetido y una vida cotidiana; es un refugio frente al tiempo cambiante y destructivo pues permite afincarse en lo igual, en lo seguro. La casa representa el espacio interior, cerrado, la protección.

Junto al exilio geográfico de la patria perdida, Zenobia padece en mayor medida un exilio interior, una falta de espacio o atmósfera de su biografía emocional, algo que ha sido destacado por la crítica. En ese doble exilio de las mujeres del 39 la casa ha sido una metáfora reincidente en la que el sujeto femenino se descubre tanto carente de patria como de identidad propia (Acillona, 2010). La exclusión de espacios públicos se compensa con la apropiación de ámbitos privados que la reconozcan y no la ignoren. Nuevamente, la casa sería "el lugar" más significado para la construcción de un sujeto perdido. Igualmente la casa es "el lugar" para saberse cuando el otro ignora la propia presencia, como sucede en los largos periodos en los que Juan Ramón la convierte en un ser invisible. Se diría que entonces el diario es también una casa donde Zenobia se recoge para verse a sí misma -la evidencia de lo que Caballé entiende como espacio cerrado del diario (1996: 100)-.

Espacios abiertos y cerrados, exílicos y patrios, exteriores e interiores, ajenos y propios, España y América... son el tránsito de Zenobia por los "lugares" y "no-lugares" de su geografía exílica.

\section{Entre dos "lugares": Diario 1. Cuba (1937-1939)}

El primer volumen de los diarios de Zenobia se inicia tras su llegada a Cuba en 1937, un 2 de marzo. La cita con el diario será constante y asidua durante todos los días del año (134 páginas) El año 1938 incluye la estancia en Nueva York y la constancia sigue siendo la nota general de sus apuntes (183 páginas). El mes de enero de 1939 recoge el último capítulo escrito en Cuba antes de salir para los Estados Unidos (14 páginas). Su ubicación en una ciudad que percibe como "no lugar" la llevarán a encontrar asiduamente en el diario "su lugar" de encuentro consigo misma.
Los cuadernos de Zenobia empiezan a escribirse el día de su aniversario de boda, 2 de marzo de 1937. En 1916 se había casado con Juan Ramón en Nueva York. Puede que sea el regreso a los inicios o la lejanía, el espacio enorme que la separa de su costumbre madrileña, la causa que origina este encuentro cotidiano con la escritura. Su discurso no expresará tanto una "crisis de identidad" (Caballé 1995: 54) cuanto la pérdida del lugar que la definía. "Hace veintiún años que nos casamos, estamos de nuevo en este lado del mar, pero tan lejos de casa". La ruptura con los paisajes y la tierra que se sienten como propios son ahora una herida abierta que solo mitiga la paz alcanzada en la bella isla. Todavía perviven imágenes vivas que se despiertan con facilidad: "nos recordó tanto a España" (1: 78) 22. Olores, flores, paisajes, jardines o pájaros suscitan, especialmente en Juan Ramón, la imagen vivificada de la España recién abandonada. En plena guerra, en julio de 1938, una música de la Escolanía de Montserrat hace llorar a ambos $^{3}$.

A veces pasa el tiempo mirando fotos de España, que después volverán a ser contempladas por el poeta. Pero el desencuentro de ambos les lleva a un recuerdo vivido por separado que ella interpreta como un camino cerrado para el acercamiento (1: 224). La memoria de España irá dividiéndose con el tiempo. Mientras Juan Ramón se aferrará a un pasado perdido, ella borrará los perfiles sentimentales del ayer para poner el corazón en su nuevo presente. Pero ahora España se recuerda con angustia y temor, incluso pavor (1:210), sin que falte un pensamiento para los millones de españoles que sienten ahora el mismo pánico que ella padeció. La huida ha abierto un futuro de incertidumbres que nunca terminará de aclararse abocados a un viaje sin fin, a veces sin rumbo.

${ }^{2}$ Zenobia Camprubí (2006) Diario 1, Diario 2 y Diario 3. En adelante citaré tomo y página.

"Las lágrimas me corrían a chorros por las mejillas antes de que se acabara y J. R. estaba secándose la cara con el pañuelo. Creo que le vi temblar la barba. Estaba deseando con toda mi alma poder oír algún día esas voces retumbando dentro de la Catedral de Barcelona y pensaba en Juanito todo el tiempo. Cuando se terminó, J.R. dijo: ‘iAy, Dios!, y que tengamos que estar en esta prisión que es estar fuera de España” (1:233). 
El contacto con los españoles expatriados es muy intenso y a través de ellos se buscan las noticias de la guerra de España, hablar de España como una profunda querencia compartida. Les duele especialmente la quiebra que en todos ha causado la guerra, los caminos rotos y sin rehacer, sobre todo cuando se evidencian en el otro a modo de espejo que refleja la propia condición. Esta inquietud se concreta en la familia de España y especialmente en el sobrino de Juan Ramón, cuya muerte les sume en una conmoción intensa. Estos diarios de navegación anotan las zozobras de un tiempo vivido en la provisionalidad o precariedad. España se siente todavía como la "casa" abandonada: "nada me hubiera hecho partir". Solo puede pensar en un futuro inmediato y este se halla a la deriva o no tiene sentido. Sin ancla, sin destino y sin tierra firme, queda desasida. Es la experiencia larga de los "no lugares".

Vamos a quedarnos aquí hasta que llegue M[ontilla]. J. R. Parece pensar que es absolutamente necesario, aunque yo no veo la diferencia entre verlo aquí, en Washington o en Nueva York, [...] Bueno, después de que venga nos vamos a la Florida y de allí zarpamos a Nueva York. Allí nos quedamos un par de meses. Después... La Florida, Buenos Aires o Europa... Eso está todo en el aire, pero los próximos tres meses sabemos dónde estaremos. (1: 177)

El exilio agudiza las penurias, como en tantos exiliados. La escasez de dinero y sus restricciones provocan la angostura espacial en unos pocos metros compartidos con el poeta, que impone su desorden, su amontonamiento de papeles y sus normas de trabajo cuando sea capaz de estar activo. Zenobia se siente ahogada y sin espacio en la habitación que comparten. El poeta invade todos sus territorios materiales y existenciales y ella va llenándose de la sensación de que no hay espacio para ella ${ }^{4}$. Le va invadiendo la sensación del "no lugar".

4 "J.R. ha logrado hacer nuestro cuarto aquí tan imposible con sus montones de periódicos viejos como nuestro piso de Madrid, y, por consiguiente, no hay espacio para libros y manuscritos. El resultado es que el sirviente solo puede entrar al cuarto una vez cada tres días, y me parece como si viviera en una pocilga" (1:188).

UNED. REI, 3 (2015), pp. 101-131
Durante el primer año de estancia, la vida en la isla se desarrolla sin apenas medios de subsistencia, en esa habitación con baño de un hotel. Zenobia contempla la belleza del mar desde la ventana, la azotea o el portal (es el mar abierto de la lejanía). Son sus momentos consigo misma que se multiplicarán a lo largo de los años reposando la mirada ante distintos paisajes. La ventana será un marco para observar la vida desde el interior de sí misma, tras la puerta. También la escritura le apuntala este espacio de vivencias interiores que constituyen el aspecto literario más rico de esta obra. Todos los enclaves de su casa son mencionados como atalayas para observar el mar, el horizonte: "mi único consuelo son las ventanas y el mar" (1:215). Sin apenas actividades propias que no sean trabajar para el poeta, Zenobia emplea su tiempo en leer y contemplar. La contemplación del mar soñando la otra orilla es la estampa arquetípica de todo refugiado. Allí pierde la mirada inactiva y anonadada en un horizonte que no puede devolverla al pasado ni sabe conducirla hacia ningún futuro. El mar será el espacio totalmente abierto a la nada.

Los espacios exteriores que le posibilitan rasgar esta clausura son muy limitados. Una de sus evasiones es el paseo asiduo por espacios abiertos, junto al mar. Estas escapadas se perciben como un alivio psicológico para su enclaustrada dependencia del poeta. El ánimo de Zenobia se revitaliza al contacto con la naturaleza y los horizontes abiertos. El mar, los paseos, la bahía no llegan a ser para ella un "lugar” pero sí le permiten salir de la angustia de su clausura física y anímica. Junto a los actos sociales y culturales que les ponen en contacto con España, se repiten las mismas relaciones sociales que la llevan de casa en casa tomando el té. Estas visitas se convertirán a lo largo de los años en un listado interminable de compromisos y nombres propios anotados como una agenda de apretadas ocupaciones sociales. Pero Zenobia siempre aspirará a otros espacios abiertos que le permitan un desarrollo intelectual y profesional.

Junto a las notas de días que juzga empequeñecidos o fracasados se van introduciendo sus sueños. El más alentador será el viaje a los Estados Unidos para unirse con su familia y sus amigos. Es el sueño 
de los espacios abiertos, la libertad. Pero la mala salud de Juan Ramón, continuamente enfermo, frena este deseo. Por fin, a finales del mes de agosto de 1938 consigue arrancarle y llevarle a Nueva York. La estancia en la casa de su hermano Joe le proporcionará los momentos de mayor plenitud de sus años americanos. Los recuerdos y su familia convierten Nueva York en un "lugar" donde se reconoce. Son días de actividad social febril que la compensan de las horas solitarias causadas por la misantropía de su marido. A finales de noviembre regresan nuevamente a Cuba, un destino que sabrá mal elegido.

El otro sueño que acompañará a Zenobia hasta el fin de sus días será el logro de un hogar. Es el sueño de los espacios protegidos. El hogar en este exilio representa el arraigo y es signo de desahogo económico. Sus búsquedas de vivienda son continuas pero topa siempre con la precariedad de sus ingresos. En sus paseos y visitas contempla con avidez los hogares ajenos. En los años que sigan, veremos que la búsqueda de vivienda es algo que se activa independientemente de la voluntad de residencia. La casa no será tanto un proyecto real como un símbolo plurisémico, inconsciente, que les delata como náufragos. El hogar en su escritura de mujer es la imagen de los espacios propios, de los cimientos de su propia identidad; sin la base del hogar no es posible explorar el mundo, ni explorarse a sí misma. Ambos sueños, viaje y nido, son en Zenobia expresión de afirmación y libertad.

\section{En la propia tierra y sin espacio propio: Diario 2. Miami- La Flo- rida $(1939-1950)$}

Este segundo diario de Zenobia se inicia con su llegada a Miami en 1939 el " 29 de enero. Domingo" y finaliza el 17 de marzo de 1950. A modo de epílogo se incluyen nueve líneas escritas el " 29 de junio. Lunes" de 1953, ya en Puerto Rico, que sintetizan el "Recuerdo del invierno 50-51". La datación de este segundo diario es irregular. De costumbre cotidiana durante 1939 (179 páginas) inicia sus lagunas en 1940 (47 páginas), al principio esporádicas y al final más extensas, de modo que desde principios de septiembre hasta fin de año solo se anotan dos días. Esta interrupción se prolonga hasta noviembre de 1943. El 15 de noviembre de este año Zenobia escribe en "Dorchester House", Washington D.C., la síntesis de los últimos años vividos. Pero el día 5 de diciembre, la urgencia por hablar del presente rompe la narración de la memoria para recuperar el comentario breve sobre el presente (12 páginas). La irregularidad y eventualidad marcan el año 1944 (9 páginas) y recupera la periodicidad durante 1945 aunque la brevedad de las notas llega en los últimos meses a la mera anotación exigua (52 páginas). Se produce otro paréntesis durante 1946 y 1947, para incorporar nuevos apuntes en julio de 1948 (5 páginas) interrumpidos hasta julio del año siguiente. En agosto de 1949, Zenobia quiebra la estructura del diario y vuelve a la memoria, pero esta vez a la memoria interior, remontándose a su infancia (22 páginas) Tres días son todo el repertorio de 1950 (6 páginas). Los Diarios cumplen así con otra de sus habituales características, la discontinuidad. El exilio impone vaivenes más fuertes que la fidelidad diaria con la escritura. También la inmersión en la corriente vital sustituye al diario como diálogo de soledades (Cortés, 1992). En esta estancia americana, la dedicación a construir "lugares" que se sientan como propios permite sustituir el "lugar" de la escritura por la realidad de la vida.

Tras una mala travesía en barco, habían llegado por fin a Miami procedentes de La Habana el 29 de enero de 1939. Las anotaciones de Zenobia durante ese primer año muestran una vida errática, a falta de un hogar y un trabajo centrado. Las páginas del diario son el único punto firme en unos años de arenas movedizas. Su primer día en Estados Unidos está ya marcado por la falta de un lugar donde alojarse; es el inicio de una carencia que la obsesiona.

Desde enero de 1939 hasta el 24 de junio de 1940 el diario de Zenobia se llena de anotaciones diarias de ritmo continuado. Se corresponden estas con los momentos de mayor inestabilidad emocional, desarraigo vital y menor actividad. Son la expresión de una espera y una frustración; días volcados en nimiedades domésticas, visitas, paseos... "no lugares". Zenobia se siente insatisfecha y sometida a una vida ajena, la de su esposo. El diario todavía sigue siendo su "lugar" 
mental para buscarse. Pero además, durante este tiempo, la obsesión por encontrar una casa llena sus páginas. La casa es el enclave posible para salvar su ser de la deriva. Junto al "lugar" interior del diario se perfila la necesidad de un "lugar" físico donde poder afincar su vida. Se sabe en su propia tierra pero debe encontrar su propio espacio.

La carencia de este hogar definitivo y la provisionalidad de su domicilio - provisionalidad general de su vida- la fuerzan a entretener sus días en las triviales cosas del acontecer diario. Cocinar, comprar ropa barata, coser sus vestidos y zurcir la ropa gastada, hacer la compra, la comida y el fregado constituyen esos "no lugares" por los que transita como de paso por una vida que siente vacía. Zenobia adormece en las actividades domésticas rutinarias y repetitivas la inestabilidad vital que le acompaña y las anota con la misma minuciosidad con que lo hace al referirse a tareas de envergadura como la traducción o la mecanografía de la obra de Juan Ramón, a las que se dedica mañana y tarde y que le arrancan alguna que otra queja por no poder salir a ninguna parte por culpa de la dependencia del trabajo. Las pinceladas domésticas se diseminan sobre el fondo de preocupaciones que dibujan las angustias reales en que se suceden sus días: recibir noticias de España a través de cartas de las que vive pendiente, esperar la llegada de los giros que le permitan trampear en su economía diaria carente de recursos, la mala salud de Juan Ramón y - en los momentos en que se permite un desahogo en el diario- el mal carácter, las rarezas y la total dependencia de su marido. Los cuadernos se dispersan en una gran fuerza centrífuga, dirigida hacia las realidades materiales y más acuciantes, una escritura de encuentro con lo inmediato que la distrae en su superficie.

En estas fechas, el mundo de los Jiménez se divide todavía entre dos continentes: atrás el pasado que quedó en España, al frente la incógnita del mañana en Estados Unidos. Así las noticias de su casa de España son siempre recogidas con todo cuidado, en especial las noticias de Guerrero, quien quedó al cuidado de la casa madrileña que abandonaron precipitadamente el escapar de la guerra. La casa de Madrid todavía significa para el matrimonio las raíces de España, el "lugar" más íntimo de su errar. Esta casa poco a poco va convirtiéndose en el único vínculo que les ata con la patria abandonada, el "lugar" en la memoria. Durante el año 1939 es constante la preocupación por el presente político de España ante las noticias del fin de la guerra. Todo el conflicto español lo han vivido a través de la prensa, los noticieros extranjeros y preferentemente la radio, escuchada en casa (en sus diversas casas), a través de cuyas ondas iban llegando los comunicados de la contienda y los desenlaces del drama. La radio será durante estos años su medio de comunicación con Europa: las emisoras de Londres, París, Roma y Berlín. Solo las ondas la conectan con mundos inaccesibles hasta los que vuela su imaginación a través de conciertos que serenan su pesadumbre. Zenobia en varias ocasiones expresa el alivio de estar lejos de la angustia del peligro que, por pocos días, ellos mismos padecieron. Las noticias - más intensas en Cuba (Palau de Nemes, 1992), y diluyéndose lentamente- también siguen llegando al hilo de las conversaciones con los otros exiliados de España, de cuyo círculo participan, aunque débilmente, a causa de la misantropía de Juan Ramón, de la que constantemente se quejará Zenobia.

Poco a poco las noticias de España terminarán casi extinguiéndose, entre la preocupación y la distancia. España es una emisora, una carta, una conversación, instalada la patria en la lejanía y la sospecha de una pérdida irremediable. Cuando su vida vaya arraigándose en Estados Unidos, de España solo llegarán algunas noticias con nombre propio, como sombras que se acercan para deshacerse en el pasado. Tras el final de la guerra, la presencia de América en Zenobia se empieza a sentir más vívida que la huella de España. Se está viviendo la metamorfosis del "lugar" patria.

A partir de ese momento, la búsqueda de casa es una huida hacia delante incontenible. En junio vuelven a ver pisos en Coral Gables. Se inicia así el hábito de visitar casas o agencias durante los fines de semana. Durante este verano la pareja vive en un estado errátil, como sin rumbo. Sobre la sombra lejana de una España cada vez más imposible se trazan otras rutas inciertas como asentarse en Miami o 
emigrar nuevamente hacia el Norte. Juan Ramón propone instalarse en Nueva York o un lugar cercano para escapar del calor que le agota sus escasas energías y para que Zenobia pueda estar cerca de su familia y hacer escapadas, "pero teniendo casa en algún sitio donde poder dejar las pertenencias y los libros y los retratos de uno y todo eso" (2: 75). Los altibajos de JR le hacen cambiar de idea a cada momento. Vivir en el sur y pasar temporadas en el norte o vivir en el norte y pasar temporadas en el sur. Son geografías ajenas sobre las que rueda indiferente.

En el aniversario del levantamiento militar, el 18 de julio, Zenobia relata la resignación del poeta para afrontar un exilio mucho más largo de lo previsto: "Sugirió ir a ver Key West, pues se va acostumbrando a la idea de prepararse a pasar un largo exilio [...] Ahora de verdad no quiere regresar a España. Quizá pueda algún día, pero dentro de mucho tiempo. La guerra decidirá la suerte o la desgracia de España” (2: 90). Acercarse hasta Key West era una muestra inequívoca de su definitiva identificación como exiliado por ser un tradicional refugio para refugiados políticos y escritores. Por el contrario, Zenobia busca entonces borrar las diferencias para consolidar su identidad americana. Ahora está utilizando en este apunte la tercera persona. Nada de esto se refiere a sí misma.

El 1 de agosto toman el barco en un camarote horriblemente incómodo cuyo único disfrute son varias duchas al día, "le hace pensar a uno en una lluvia suave y continua, en vez de un aguacero" (2: 96). El 4 de agosto atracan en Nueva York y esa expectativa tiene feliz y ansiosa a Zenobia. Se instalan en la casa de la familia, lo que le proporciona un sentimiento de alivio ya que, tras la deriva de los últimos años, encuentra un espacio agradable y un lugar que siente como propio: "Este cuarto es muy cómodo y es una satisfacción el que JR y yo estemos juntos en un lugar propio, independiente, sin ser una carga para nadie" (2: 97). Nueva York será su destino predilecto, su espacio elegido. La ciudad moderna, de pluralidad social, que neutraliza al individuo, es la ciudad con la que se identifica, el impulso que le dinamiza y le permite recuperar un sentido de utilidad carcomido junto al poeta. Nueva York es mucho más que una ciudad en la que recordar su juventud pues simboliza la libertad, el espacio frenético que permite la individualidad y lo heterogéneo. "Cosa inimaginable para el soñador de casas: Los rascacielos no tienen sótano" (Bachelard, 2000: 45), pero Nueva York se opone al espacio íntimo de la casa, es su contrapunto, público y anónimo. Perderse en los "no lugares" es su modo de reencuentro.

El encuentro con su familia y los paseos por la playa (mar de los espacios abiertos a la vida) junto a la residencia de verano la reconfortan y le permiten vivir unos días plenos. Por un breve tiempo la estabilidad y la seguridad iluminan el largo período de soledad e itinerancia que venía viviendo. Deja alojado a Juan Ramón en la casa habitual donde se hospedaban los hispanistas en sus estancias en Nueva York y donde ellos se alojaban en esa ciudad, y pasa quince días sola con su familia. Liberada del peso emocional de su esposo y de las responsabilidades de todo tipo que este le cargaba, estos días de agosto le permiten un ambiente de comunicación y apertura social con su familia. Las entradas de estos días cambian radicalmente su tono vital, se muestra pletórica, anota detalladamente todos los contactos mantenidos, y cumple el sueño de contemplar el mar y bañarse en la playa. Son actos que recuperan por breve tiempo su juventud y su libertad. El diario se escribe en primera persona, ella ocupa su centro $\mathrm{y}$, por primera vez, apenas menciona a JR o su recuerdo, borrándose la agobiante preocupación por él que poco antes la acosaba y emergía en cada línea. Juan Ramón deja por fin de ser el protagonista de sus diarios. Las entradas de estos días solo hablan de familia y amigos, cócteles, tés, cenas, comidas, paseos... Transita, como en Nueva York, por los "no-lugares”. Quizá porque estamos “más seguros en las calles donde no habitamos más que de paso" (Bachelard, 2000: 56). Es una de las pocas veces en que podemos escuchar la voz de Zenobia sin perturbaciones que la disturben. La breve separación de Juan Ramón ha cambiado la angostura del encierro por la libertad de los espacios abiertos. Esa libertad la define mejor que en ningún otro momento, su familia le permite saberse ella, enraizada e independiente. Disfruta de la vida, el mar, el bosque, los paseos por la naturaleza. Aunque pa-

UNED. REI, 3 (2015), pp. 101-131

ISSN 2340-9029 
sajeros, estos días son el momento por excelencia en los largos años americanos.

El día 30 regresa por sorpresa y encuentra a Juan Ramón triste y cabizbajo, incapaz de vivir sin ella, rehusando todo tipo de visitas o compromisos. Los días que disfrutan juntos en Nueva York se relatan con tono positivo, pero en septiembre Zenobia vuelve a escapar a Massachussets, donde sigue disfrutando de excursiones, relaciones y gentes, otra vez liberada de la dependencia diaria que le impone su marido. A su regreso, Juan Ramón vuelve a suspirar de satisfacción al verla regresar sumiéndola nuevamente en la atadura. Su agotamiento crónico la agobia. Todos los planes se rompen y se frustran por su causa. Es un peso enorme del que no se atreve a quejarse directamente. Y esto la hace consciente de que cualquier tipo de vida normal resulta imposible. "Juan Ramón está cansado todo el tiempo. Estoy convencida de que no tiene remedio. En él la vida animal es más débil que en cualquier otra persona que conozco, a excepción, quizá, de la mayor parte de los tuberculosos" (2: 119). Aunque la ciudad es el lugar de un nuevo dinamismo y actividad, la presencia de Juan Ramón la convierte en espacio encadenado de posibilidades frustradas 5 . "Me deprime la clase de vida que J. R. hace en Nueva York y el esfuerzo que significa hacer la vida que de otro modo sería mi vida normal. Me parece que tengo que gastar más de lo que quiero gastar para vivir una clase de vida que no me gusta" (2: 121), escribirá el 19 de septiembre. La frustrada experiencia urbana la empuja a encontrar una casa donde su vida encuentre algo propio y menos dependiente.

${ }^{5}$ Mientras ella entra al Museo de Arte Moderno, él la espera fuera por no poder resistir la visita. Cansada, comenta que tuvieron que coger un autobús para volver a casa. "Lo único que quiere hacer J. R. es quedarse sentado en el cuarto o comer en uno de esos lugares imposibles. Tampoco quiere alquilar el apartamento de Mr. Owre y prefiere un lugar menos tropical que Miami" (2: 119). Al día siguiente el poeta se acatarra por una corriente y Zenobia siente la carga de esta convivencia: "no sé por qué trato de que J. R. haga nada conmigo" (2: 120).
Por eso perder la ocasión otra vez le lleva al borde de la crisis el 20 de septiembre 6 .

La toma de contacto con este umbral de actividad urbana le ha permitido tomar conciencia de la verdadera situación a la que la convivencia dependiente con su esposo la condena. Recuperados otros horizontes, aletargados por la inercia y el aislamiento a que la vida cotidiana la tienen atada, el diario se hace expresión consciente de dos voluntades enfrentadas. La posesión sutil a la que se ve sometida solo puede verse compensada en la cita con la escritura, que se convierte así en el punto para la queja, en el relato de una lucha a la que no puede poner final.

Y es que este viaje ha abierto un cambio en los paisajes interiores: a la anterior fijación por la casa ("lugar" estático y seguro) le han sucedido los dinámicos y fugaces espacios "no-lugares” urbanos. La autora cita detenidamente todas las cafeterías, restaurantes, drugstores, etc., donde desayuna o almuerza y dedica una especial atención al mundo de los Museos. La visita a las exposiciones que llegan a NY o los diletantes recorridos por el Museo Moderno son la afición artística más relevante de Zenobia. Muestra especial admiración por la pintura, que observa con veneración y culto. En esta sensibilidad exquisita había destacado desde muy joven. Como si fuera el diario de un artista, el diario cambia el registro doméstico y empobrecido y adopta el fino saber de un crítico de arte. Así se embelesa con el período azul de Picasso, contempla sus arlequines y retiene de su visita a la Feria dos cuadros espectaculares: "El Cristo acallando la tempestad de Tintoretto, habitualmente en la colección Sacks, y la cabeza de Cristo en los brazos de la Virgen, espléndida e irrepetible, pintada

6 "Una carta de los Owre me sumió en un nuevo estado de depresión. Consiguieron el apartamento que yo quería y J.R. ni siquiera quiere pasar este año en Miami. Fuimos a ver al agente de Clyde Mallory, pues quiere irse lo antes posible. Yo también, porque me enferma verlo tan impaciente por marcharse. Dice que quiere trabajar, lo que de veras significa que yo renuncie a todo lo que quiero hacer y pase cada momento de mi vida resolviendo sus problemas y renunciando a toda posible distracción" (2: 121).

UNED. REI, 3 (2015), pp. 101-131

ISSN 2340-9029 
como solo podía hacerlo el Greco" (2: 124-125). Los cuadros son para ella instantes de plena belleza que se prolongan en el texto emocionado del diario como guardando fugaces horas de plenitud. La emoción estética gratifica su vida de exiliada y le permite trascenderla como el poeta la trascendía también estéticamente a través de la poesía. La ciudad anónima de los rascacielos se sublima en estos éxtasis artísticos.

Nacido de la fuerza moral adquirida tanto como de la necesidad económica, se inicia un nuevo período en la vida de la autora que se caracteriza por la construcción de un espacio personal más satisfactorio y un "lugar" de integración que la vincula definitivamente con los Estados Unidos. Llegan una nueva actividad centrada en sus conferencias y un nuevo compromiso editorial del que solo se va anotando el trabajo realizado, las rutas turísticas de España a través de castillos y monasterios. Sobre ello volverá en varias ocasiones en las que menciona la literatura análoga o los comentarios realizados. "Estoy aprendiendo mucha Historia Medieval y poniendo fechas". Pero estas alusiones no se tiñen de memoria o nostalgia de la tierra lejana sino que recogen la eficacia de la tarea emprendida, el avance práctico de su proyecto. Las referencias a libros, lecturas e interesantes bibliografías empiezan a llenar a partir de ahora las páginas de su diario, volviendo a adquirir el registro del diario de un intelectual. El diario ya no solo es interesante para recrear la gestación de la obra de su marido sino que enfoca su atención en sus propias tareas. Los tímidos pasos se irán convirtiendo en grandes conquistas gracias a su voluntad: "Siento aún el peso de las conferencias, no me siento segura y constantemente estoy rehusando invitaciones [...], seguro que si hubiese tenido éxito me habrían llegado muchas invitaciones más. Debo tener el coraje suficiente para probar" (2: 189). Estas impresiones del 17 de febrero se ratificarán en abril a raíz de la conferencia en Orlando en la que se siente muy nerviosa, insegura, al no estar a la altura de Juan Ramón. Esta inseguridad la devuelve al hogar como un refugio ante la responsabilidad recién adquirida: "Nos alegramos de regresar a nuestro dulce, sencillo, alegre, casi divertido piso alto" (2: 201). Pero su tesón, la necesidad económica y el amor propio de no depender de nadie, la terminarán llevando a un futuro profesional en el que se sienta segura y realizada.

Si los paisajes históricos de España no despiertan sentimientos de añoranza, tampoco lo hace la memoria de los espacios dejados atrás. Zenobia se siente arraigada en tierra americana y su exilio se está convirtiendo en emocional, interior, no patrio. Añora la familia y los recuerdos de años pasados. La soledad no es una experiencia de la lejanía sino de los afectos más cercanos. El día de Acción de Gracias se vive íntegramente desde sus raíces americanas, tan ajenas a las costumbres españolas: "No sentí la soledad que me sobrecoge en días como la Navidad y el Año Nuevo, etc. en los que me encuentro lejos de la familia y nadie a mi alrededor se preocupa en lo más mínimo" (2: 155). Las fechas de Navidad, por el contrario, permiten un recuerdo de Madrid para evocar la soledad que ella percibió allí años atrás?

$\mathrm{Y}$ evocando las costumbres tradicionales de su familia y el testigo tomado por su hermano Joe, expresa más bien el desarraigo sentido en España y la incomprensión de Juan Ramón hacia un mundo que no era el suyo: “Temo que nunca será lo mismo en este país, y en Madrid no teníamos familia; además Juan Ramón no entiende estas cosas" (2: 155). El arraigo en un hogar americano acentúa la distancia entre ambas vivencias del exilio: mientras Juan Ramón se siente desenraizado lejos de España, Zenobia solo se lamenta de los desgarros afectivos vividos en un lugar que siente suyo y en el que ve estabilizarse a su marido. "Si no fuera por las tragedias pasadas, creo que J R estaría más cómodo y contento aquí que en cualquier otro lugar” (2: 157). Las relaciones sociales que establece son básicamente americanas. A partir de este momento su atención a la vivienda será un tema de integración social y especialmente una inversión económica que mejore sus finanzas.

7 "Me va a recordar aquella Navidad en Conde de Aranda, cuando me sentía tan sola y salimos a ver las carpas de Navidad en la plaza de Santa Cruz y los alrededores [...] y mi aislamiento en días como esos me partía el alma, acostumbrada a la alegría de mi extensa familia en los EE.UU. Con mamá en España nos sentíamos tristes las dos y yo le adornaba un árbol de Navidad como si hubiera sido mi propia hija" (2: 168-169).

UNED. REI, 3 (2015), pp. 101-131

ISSN 2340-9029 
Desde noviembre de 1939 la estabilidad de un nuevo domicilio parece sentar bien al matrimonio. Juan Ramón amanece radiante y madruga para escribir. "Las casas blancas, los tejados de tejas y los pinos le recuerdan a Moguer y sus ansias fluyen en verso. Suerte que pueda ver Moguer a la distancia” (2: 146-147). Su obra poética nace de la memoria de los paisajes de la infancia que se evocan desde otro dulce espacio. El espacio poético nace de un espacio estático, fijo en el tiempo. El resultado fue Romances de Coral Gables (1939-1942). Frente a esta efervescencia creadora del poeta, Zenobia debe atender primero una serie de realidades domésticas que refiere con cuidado. En las notas del día 14 apunta el inventario de mantelerías, plata, cristalería, vajilla y cacerolas. Zenobia atiende a lo inmediato. Los objetos de la casa no son sino la mera representación del hogar como espacio para sus propias necesidades y actividades. Liberada ya de estas tareas y sintiéndose dueña de su persona al ser dueña de un espacio, es capaz de enumerar la lista de preferencias a las que, por fin, ya instalada, podrá dedicarse. Y estas son casi todas de carácter intelectual y social: club de Damas y la Biblioteca, enseñar español, clases de cocina, decoración, Saturday Evening Post, ampliar fotografías, hospitalización, Mrs. Kraai, tratar de escribir para ganarse la vida, conferencias y diapositivas. El pragmatismo impera en este listado de objetivos que se plantean, ahora sí, desde una primera persona con una voluntad independiente que luego la convivencia con Juan Ramón se encargaría de recortar. Todos los proyectos se abren a los lugares exteriores, comunes, compartidos.

Esta casa es para Zenobia un estribo de acceso a una expansión de crecimiento intelectual y profesional: la lectura literaria y de actualidad, la escritura y las conferencias como formas de obtener ingresos, la enseñanza como medio de vida. "Este será nuestro verdadero lugar de trabajo porque podemos aislarnos mejor" (2: 158). El espacio cerrado es un espacio interior dispuesto para el crecimiento personal que antes quedaba ahogado. El hogar es el impulso de una etapa de activo trabajo compartido: se reúne ya la obra para componer otro tomo; terminan "Poesía y Literatura" y preparan conferencias y se- minarios"; leen en casa y empiezan a asistir a algunos conciertos que tanto alimentan su espíritu artístico. Para Juan Ramón este arraigo es motivo de conexión y puente interior con sus raíces andaluzas que le impulsan su ejercicio creador: "El paisaje y la tranquilidad lo hacen regresar a Andalucía con gran anhelo y nostalgia" (2: 179). En Coral Gables se ha hecho posible la tensión exacta que permite al sujeto transitar de interior al exterior y viceversa.

Una de las decisiones más importantes de estos años es la de iniciar una vida académica y una carrera profesional propia. Ha sido una decisión interrumpida que había sido madurada en la soledad de su escritura. Con ello no solo quiere hacerse cargo de su independencia económica sino que quiere dar un sentido a su vida. En 1944 se inicia como lectora visitante en la Universidad de Maryland. Ocupan entonces un apartamento en Dorchester House. Los 2.000 \$ de sueldo como profesora consiguen un ambiente de serenidad y la pareja parece vivir momentos de armonía, pese a la oposición inicial del poeta a su trabajo como docente. Los diarios muestran que Zenobia toma resoluciones en soledad, al margen de su esposo, y que la escritura actúa como un espacio propio en el que aquilatar pensamientos y voluntades. A partir de estos momentos, la actividad académica y sus continuas ocupaciones domésticas apenas dejan tiempo para los apuntes en el diario. No obstante, mantiene brevísimas notas de dietario que no interrumpen cronológicamente la escritura. En estos años en que se conjugan el espacio público y el mundo interior, Zenobia vive momentos de equilibrio personal: "Me encanta mi doble vida: la mitad en la universidad y la otra mitad dedicada a la vida doméstica" (2: 264). La actividad le proporciona felicidad, una felicidad brindada por una energía en dispersión, centrífuga. Los compromisos sociales se multiplican y la integración en la sociedad americana es total. Durante estos años ya no existe ni remota mención de España ni su pasado. Por el contrario, se mencionan posibles viajes a Hispanoamérica para que Juan Ramón pueda sintonizar con un ambiente hispánico que necesita prontamente para revivir. 
Volcada en el presente, su vida está ya hecha en los Estados Unidos. Ha construido su nuevo "lugar" y ahora comprarán, en 1949 , una casa en Riverdale, cerca de College Park, donde se encontraba la Universidad. Es la casa de Queensbury Road 4310. Junto a la casa, la compra de un coche que solo ella conduce metaforiza la conquista de los espacios públicos y abiertos. En febrero percibe la nueva seguridad que esta condición ha ido creando en su personalidad: "Descubrir constantemente que tengo más capacidad que la que me atribuyo, debe hacerme sentir más serena en la vida". Pero, una vez creado el "lugar", conseguido el sueño de una bella casa y la libertad de los desplazamientos, volverá a sentirse agobiada por su pequeñez burguesa. La insatisfacción emocional vuelve a lastimarla.

\section{«Sola con mis pensamientos»: Diario 3. Puerto Rico (1951-1956)}

Un brevísimo epílogo, escrito el "29 de junio. Lunes" de 1953 ya en Puerto Rico (donde solo menciona la enfermedad de Juan Ramón, su escisión entre su cuidado y sus obligaciones académicas y su traslado forzoso a Puerto Rico) sirve de enlace con el diario que Zenobia había iniciado en octubre de 1951. Breves y serenas anotaciones durante el otoño, ensombrecidas hasta la antesala de la operación (diez páginas) y apuntes dispersos a lo largo de 1952 (12 páginas) mermarán extraordinariamente en 1953, en que la enfermedad y los nuevos tratamientos reaparecen ( 5 páginas). Irán ampliándose en momentos de mayor sufrimiento y preocupación en 1954 (36 páginas) hasta convertirse en cita asidua con el diario durante todo el calmado y laborioso 1955 (144 páginas). El último año de su vida Zenobia escribe hasta el 13 de septiembre (146 páginas). En Puerto Rico la autora obtiene su nacionalidad americana pero esa conquista tras años de intentos deja indiferente su espíritu. España brota de nuevo del recuerdo desvaído y se abre de nuevo en añoranza. El verdadero "lugar" ante la muerte es el lugar del origen. España vuelve a ser el sueño del regreso.

El día 20 de septiembre regresaba sin ninguna esperanza a Puerto Rico para ingresar en una clínica donde moriría semanas más tarde.
Los meses de enfermedad y reclusión devuelven a Zenobia a las páginas en blanco de su diario como una cita consigo misma y como sujetando en palabras el hilo de una vida que se le está yendo irremediablemente. El diario la acompaña casi hasta el final de sus días.

La víspera de su operación en Boston, sola totalmente ante los acontecimientos escribía: "Por fin estoy sola con mis pensamientos". La ciudad se recoge en la solitaria habitación de una clínica, un angustioso "no lugar". Esta frase encierra el tono del diario más rico de cuantos escribió, mucho más atento a los sentimientos que a las actividades. En esta tercera etapa de Puerto Rico el diario se aquieta en la intimidad profunda del sujeto. Se alcanza por fin plenamente la primera persona. La temporalidad del diario se vive en su máxima intensidad pues cada día es un regalo ante un futuro acechado de peligros. La maduración literaria se ha producido a la par de la maduración personal. "La vida está llena de nuevo" (3: 28).

La última etapa de los diarios de Zenobia en Puerto Rico toma un sentido dramático pues desde el primer momento concurren dos circunstancias angustiosas en su nueva vida isleña. La placidez del nuevo paisaje resulta dolorosa ante las turbulencias que vive en su espíritu. Parece haber encontrado la paz y el lugar ideal de una vida serena pero la enfermedad pone a Juan Ramón al borde de la muerte o de la enajenación mental mientras ella enfrenta casi en solitario el diagnóstico de un cáncer que durante cinco años la enfrenta a la incertidumbre del futuro y una progresiva pérdida de fuerzas. El diario de Zenobia es entonces una reconciliación con el poeta y consigo misma. Afloran ahora las últimas verdades del corazón y las últimas confesiones del propio yo. Es la hora de la verdad y el diario es el espacio donde expresarla. Frente a la huida de la "celda" de los diarios de Cuba, los diarios de Puerto Rico son la huida de una trágica opresión del tiempo. Si los textos autobiográficos oscilan entre el sentimiento de transcurso del tiempo y la búsqueda de significado del tiempo pasado (May, 1982: 47) las etapas de Cuba y Estados Unidos responden con una construcción de tiempo futuro mientras que la de Puerto Rico representa la voluntad de salvar lo ya vivido en el pasado.

UNED. REI, 3 (2015), pp. 101-131

ISSN 2340-9029 
El matrimonio con Juan Ramón hace balance y muestra su profunda cara. El tiempo ha asentado los sentimientos inestables de años atrás. “¡Cómo se da uno cuenta de que se quiere más y más a medida de que pasan los años. Es porque se da uno cuenta al mismo tiempo de que le va ya quedando poco de estar juntos" (3: 27-28). Y también adivinamos el verdadero carácter de ese amor: "Mi único hijo J.R". Las crisis insoportables de un poeta enajenado en muchos momentos se viven con tolerancia, paciencia y preocupación maternal. Ante su propia muerte se angustia por dejar desprotegido a un ser totalmente desvalido. No se equivocaba.

La pareja encuentra en la isla un nuevo espacio de acercamiento a lo hispano, precipitado por la crisis que sumió a Juan Ramón en un pozo sin salida durante los últimos meses de Washington. Los médicos aconsejaron como única posible solución para sus males el acercamiento a un lugar de trato grato y familiar que acogiese al poeta en su propia lengua y Zenobia abandonó su situación estabilizada en la Universidad de Maryland y su hogar agradable cerca de esta. Cuando llegan a Puerto Rico, su situación económica se vuelve precaria nuevamente y comparten vivienda con el doctor García Madrid con el que se dividen la casa. Pese a que la preocupación se centra ahora en la recuperación de su marido, no puede evitar varios comentarios acerca de las limitaciones de habitar la nueva vivienda en compañía. Dos años más tarde, en el verano de 1953, el matrimonio del doctor provoca el cambio de domicilio y se desplazan a Hato Rey, muy cerca de la Universidad. Explica Graciela Palau cómo encontraron su hogar a través de un anuncio que alquilaba el bajo de una casa en el residencial barrio de Floral Park especificando que se trataba de un vecindario de médicos. Sin embargo, Zenobia ya no presta atención en el diario, como en otros tiempos, al relato sobre la búsqueda y avatares del nuevo domicilio. El amago de un nuevo cáncer y la depresión en que esto la sume, las nuevas hospitalizaciones y tratamientos, el fallecimiento de cáncer de su hermano Augusto y de su prima Hanna justifican sin duda el silencio casi total de ocho meses en el diario de 1953, en el que solo caben los apuntes del día 24 de marzo.
No reanuda la escritura hasta el 19 de agosto y lo hace para detenerse precisamente en la nueva casa detallando algunos pormenores ${ }^{8}$. Quizá por llenar de vida y recuerdos el nuevo espacio para luchar así con la muerte, Zenobia escribe: "hoy he sacado algunas fotografías y las he colocado en los todavía escasísimos muebles, empieza esto a tener un aire vivido" (3: 34). No habrá ya más comentarios salvo la confianza de que este nuevo hogar, el último, sea el lugar que permita desarrollar la obra de Juan Ramón: “Dios permita que esta instalación nueva para nosotros pueda cooperar bien a la organización del trabajo de J.R." (3: 34). El mismo día que se instalan, un 13 de septiembre, vuelve a ser la ocasión para retomar su diario. La casa y la escritura aparecen nuevamente compartidas. Con la conciencia de marcar un nuevo hito en su vida, consigna su nueva ubicación: "Hato Rey, 13 de setiembre. ¡Primer domingo en nuestra casita desde que se iniciaron nuestras peregrinaciones en agosto del 50!" (3: 35). No cabe duda de que Hato Rey significó un espacio crucial, su refugio personal, en los años siguientes en los que cada día significaba la conquista de la vida frente al tiempo. Zenobia disfruta ahora de instantes contemplativos, poéticos, en esta nueva habitación de Hato Rey, convertida en un observatorio para admirar la belleza exterior. Esta contemplación meditativa es profundamente lírica. La vida vuelve a admirarse desde la ventana, en soledad y silencio, como antes divisó desde la azotea cubana los días de exiliada sin tarea ni lugar. Esta nueva tristeza nace del hilo débil de la vida enferma, convertido el paisaje en éxtasis:

$\mathrm{Al}$ otro lado de las ventanas laterales de mi dormitorio donde me siento, la mata de flores de pascua - que más parece un árbol - está en florido resplandor. Sobre la larga línea baja del chalé blanco vecino se ve un alto tulipán africano salpicado de brillantes campanillas. Unas tejas, oscurecidas como corteza de árbol por la humedad, ponen en relieve la parte de arriba de las dos ventanas de la casa de

${ }^{8}$ Es el primer día que ha ido con Francisco a la nueva casa, sin Juan Ramón, y han podido presenciar la destrucción del seto vecino para la construcción de otra vivienda inmediata.

UNED. REI, 3 (2015), pp. 101-131

ISSN 2340-9029 
mi vecino que se ve desde mi asiento. Por la ventana, a la izquierda, más paredes blancas, verdor, nubes iluminadas por el sol. La belleza natural de esta isla debiera ser suficiente para calmar mi espíritu. ( 2 de enero [Este diario está escrito en inglés]) (3: 40)

La pérdida de salud de ambos angustia a Zenobia que vive con dolor insoportable las crisis de Juan Ramón. Si ella falta Juan Ramón deberá encontrar un lugar donde alguien se ocupe de él. La incertidumbre y pesadumbre ante el futuro le hacen pensar en España como destino. Esta idea recurrente le impulsa a tomar continuos contactos para tantear posibilidades que van haciéndose cada vez más cercanas. El relato del diario se detiene en los pensamientos del posible retorno. El tono esperanzado parece anunciar el final de un largo viaje. Desea pasar los últimos años junto a Juan Ramón, en una especie de regreso emocional a los orígenes de su relación, un espacio de nostalgias. Por otra parte, la geografía y la abundante familia de Juan Ramón serían una forma de proporcionarle el entorno afectivo que precisa para su curación, para volver a ser "él mismo". La vuelta a Europa es insinuada ya por Guillermo de Torre en agosto de 1952. Un año más tarde los diarios se van llenando de alusiones al regreso. La España perdida en el recuerdo empieza a ser un futuro posible ahora que Zenobia ya ha obtenido la nacionalidad americana.

Al año siguiente su salud empeora, ya no podrá empezar el nuevo curso y se reavivan angustias económicas por los impagos de las editoriales. La realidad social de España choca con la ensoñación del espacio recordado. "La vuelta a España no quiere ni considerarla. A mí tampoco me hace mucha ilusión por la beatería de la gente, que, sobre todo, con mi amenaza actual, no me dejaría en paz ni un momento. A mí no me sabría mal vivir en Mallorca [...]" (3: 40).La isla, la mar del descanso, se abre como aislamiento borrando ya fronteras entre "lugares" y "no lugares". Sin embargo, en mayo de 1955, con el proyecto de la casa de Juan Ramón en Moguer, España empieza a concretarse: "Pienso más y más en la posibilidad de volver a Sevilla para terminar allí apaciblemente nuestros días; es en donde Juan Ramón tiene más familia cercana y muy buenos amigos" (3: 97). En junio el contacto con un sobrino del poeta empieza a definir la fecha del próximo verano para un posible viaje. La noticia de que la casa de Juan Ramón había sido adquirida para constituir una Biblioteca-Museo es acogida con el júbilo de quien pone fin a una diáspora. España sería la última casa, la definitiva. "Dios parece protegernos a cada paso". Zenobia soñaba con su último y definitivo hogar, Moguer, el origen, el origen de Juan Ramón al que ligaba al fin su propio espacio.

Podemos concluir que en los largos y duros años de exilio americano, los diarios han constituido el auténtico espacio de encuentro consigo misma, el "lugar" utópico donde recogerse como en un verdadero hogar y donde transitar como en un verdadero viaje. En su deambular geográfico y emocional, América se abrió como la realidad posible, un nuevo "lugar" (algo que jamás compartiría Juan Ramón, atado al imposible de la nostalgia), pero, ante la inminencia de la muerte, fue al fin España, el viejo espacio del recuerdo, el único "lugar" definitivo que podía cerrar para los dos aquel deambular exílico.

Recibido: 04/05/2015

Aceptado: 02/07/2015

\section{Referencias bibliográficas}

Acillona López, Mercedes (2010), "La casa y la memoria en los textos autobiográficos de las escritoras del exilio", en Mercedes Acillona, coord., Sujeto exílico: epistolarios y diarios, San Sebastián: Hamaika Bide Elkartea, pp. 303-329.

Alberca Serrano, Manuel (2000), La escritura invisible. Testimonios sobre el diario intimo, Oiartzun: Sendoa.

Augé, Marc (1995), Los no lugares, espacios del anonimato: una antropología de la sobremodernidad, Barcelona: Gedisa.

UNED. REI, 3 (2015), pp. 101-131

ISSN 2340-9029 
Bachelard, Gaston (2000), La poética del espacio, Buenos Aires: Fondo de Cultura Económica.

Bravo Vega, Julián (2000), “Memoria de la melancolía (1970) de Ma Teresa León: la memoria femenina del exilio español y el proyecto de construcción autobiográfica”, en Marina Villalba Álvarez ed., Mujeres novelistas en el panorama literario del siglo XX. Cuenca: Ediciones de la Universidad de Castilla-La Mancha, pp. 149-162.

Caballé, Anna (1995), Narcisos de tinta: ensayos sobre la literatura autobiográfica en lengua castellana (siglos XIX y XX), Málaga: Megazul.

--- (1996), “Ego tristis. El diario íntimo en España”, Revista de Occidente, 182-183, pp. 99-120.

--- (2012), “Pasé la mañana escribiendo: el diario de Zenobia Camprubí (1937-1956)", RILCE, 28, 1, pp. 57-73. http://dadun.unav.edu/ handle/10171/29300 (última consulta 30-04-2015).

Camprubí, Zenobia (2006a), Diario.1. Cuba (1937-1939), trad., introd., notas de Graciela Palau de Nemes, Madrid: Alianza Editorial/ La Editorial, Universidad de Puerto Rico.

--- (2006b), Diario. 2. Estados Unidos (1939-1950), trad., introd., notas de Graciela Palau de Nemes, Madrid: Alianza Editorial/ Río Piedras: Universidad de Puerto Rico.

--- (2006c), Diario. 3. Puerto Rico (1951-1956), trad., introd., notas de Graciela Palau de Nemes, Madrid: Alianza Editorial/ La Editorial, Universidad de Puerto Rico.

Catelli, Nora (1996), "El diario íntimo: una posición femenina”, Revista de Occidente, 182-183, pp. 87-98.

Cedena Gallardo, Eusebio (2004a), El diario y su aplicación en los escritores del exilio español de posguerra, Madrid: FUE.

Cedena Gallardo, Eusebio (2004b), "Exilio y vida: los diarios de Zenobia Camprubí”, en María Ángeles Hermosilla Álvarez y Celia Fernández Prieto eds., Autobiografía en España, un balance, Madrid: Visor, pp. 343-360.
Cividanes, Ame (2000), El exilio interior-exterior en la obra de Rosa Chacel, María Teresa León y Mercé Rodoreda, Ph.D Dissertation, The Florida State University. http://search.proquest.com/docview/304591060 (última consulta 30-04-2015).

Cortés Ibáñez, Emilia (1997), “Zenobia Camprubí en su diario de Estados Unidos”, Signa, 6, pp. 119-138. http://www.cervantesvirtual.com/servlet/SirveObras/02483887547248618976613/p0000002. htm\#I_10_(última consulta 30-04-2015).

---, ed. (2008), Mujer y escritura autobiográfica: Zenobia Camprubí, Huelva: Los libros del Trienio.

---, coord. (2010), Zenobia Camprubí y la Edad de Plata de la cultura española, Sevilla: Universidad Internacional de Andalucía.

--- (2010), “Zenobia Camprubí: Una vida entre España y América”, en Emilia Cortés Ibáñez, ed., Zenobia Camprubí y la Edad de Plata de la cultura española, Sevilla: Universidad Internacional de Andalucía, pp. 43-68. http://hdl.handle.net/10334/2446 (última consulta 30-042015).

Gil Muñoz, Arantza (2007), “Pobre Zenobia! Vivir con Juan Ramón”, Per Abbat , 2, pp. 111-114. http://dialnet.unirioja.es/descarga/articulo/2210234.pdf (última consulta 30-04-2015).

Gozálvez Escobar, José Luis, coord. (2009), Zenobia con luz propia, Moguer (Huelva): Fundación Zenobia JR y Universidad Internacional de Andalucía.

Grillo, Rosa María (2001), “Juegos de parejas en un espejo. Masculino y femenino en la escritura autobiográfica del exilio”, en José María Balcells y José Antonio Pérez Bowie eds., El exilio cultural de la guerra civil (1936-1939), Salamanca: Ediciones Universidad de Salamanca, pp. 323-342.

Inestrillas, María del Mar (2002), Exilio, memoria y autorrepresentación: la escritura autobiográfica de María Zambrano, María Teresa León y Rosa Chacel, Ph.D Dissertation. The Ohio State University. 
https://etd.ohiolink.edu/!etd.send_file?accession $=$ osu1039017903\&d isposition=inline (última consulta 30-04-2015).

Mangini, Shirley (1997), Recuerdos de la resistencia: la voz de las mujeres de la guerra civil española, Madrid: Península.

Martínez, Josebe (2007), Exiliadas. Escritoras, Guerra civil y memoria, Barcelona: Montesinos. https://books.google.es/books/about/ Exiliadas.html?id=NlL20N8cnQUC\&redir_esc=y (última consulta 30-04-2015).

Masanet, Lidia (1998), La autobiografía femenina española contemporánea, Madrid: Fundamentos.

May, George (1982), La autobiografía, México: Fondo de cultura Económica.

Palau de Nemes, Graciela (1992), "La guerra civil en el diario de una exiliada: Zenobia Camprubí de Jiménez", en Antonio Vilanova coord., Actas del X Congreso de la Asociación Internacional de Hispanistas, Barcelona 21-26 de agosto de 1989, Barcelona: PPU, t. III., pp. 141-148. http://cvc.cervantes.es/literatura/aih/pdf/10/aih_10_3_016. pdf (última consulta 30-04-2015).

Rodrigo, Antonina (1999), Mujer y exilio. 1939, Madrid: Compañía Literaria.

Romera Castillo, José (2006), De primera mano. Sobre escritura autobiográfica en España (siglo XX), Madrid: Visor Libros.

--- (2010), "Escritura autobiográfica de mujeres del 27 en el exilio", en Margarita Almela Boix, Brigitte Leguen Peres, Marina Sanfilippo eds., Universos Femeninos en la Literatura Actual. Mujeres de Papel, Madrid: UNED, pp. 175-190. http:// books.google.com (última consulta 30-04-2015).

Saiz Viadero, José Ramón (2010), “Zenobia Camprubí y las republicanas en el exilio", en Emilia Cortés Ibáñez, ed., Zenobia Camprubí y la Edad de Plata de la cultura española, Sevilla: Universidad Internacional de Andalucía, pp. 308-328. http://hdl.handle.net/10334/2456 (última consulta 30-04-2015).
Zabala Aguirre, José Ramón (2007), Non zeuden emakumeak. La mujer vasca en el exilio de 1936, Donostia: Saturrarán. 